\title{
Editoriales independientes en Chile: una política "literaria" del escritor-editor
}

Presses indépendantes au Chili: une politique "littéraire " de l'écrivain-éditeur Independent publishing houses in Chile: the "literary" politics of the writerpublisher

\section{Rafael Farías Becerra}

\section{CpenEdition}

\section{Journals}

Édition électronique

URL : https://journals.openedition.org/ideas/1885

DOI : 10.4000/ideas. 1885

ISSN : 1950-5701

Éditeur

Institut des Amériques

Référence électronique

Rafael Farías Becerra, "Editoriales independientes en Chile: una política "literaria" del escritor-editor », IdeAs [En ligne], 9 | 2017, mis en ligne le 13 juillet 2017, consulté le 18 octobre 2022. URL : http:// journals.openedition.org/ideas/1885; DOI : https://doi.org/10.4000/ideas.1885

Ce document a été généré automatiquement le 18 octobre 2022

\section{cc)}

Creative Commons - Attribution - Pas d'Utilisation Commerciale - Pas de Modification 4.0 International - CC BY-NC-ND 4.0

https://creativecommons.org/licenses/by-nc-nd/4.0/ 


\section{Editoriales independientes en Chile: una política "literaria" del escritor- editor}

Presses indépendantes au Chili : une politique « littéraire " de l'écrivain-éditeur Independent publishing houses in Chile: the "literary" politics of the writerpublisher

Rafael Farías Becerra

\section{Introducción}

1 La política de la literatura no es la política de los escritores, ha señalado Jacques Rancière haciendo referencia a aquella gran "revolución" que significó la aparición de la literatura alrededor del siglo XVIII y comienzos del XIX. El surgimiento de la literatura traía consigo el derrumbe de los fundamentos principales que regían el sistema "representativo" de las artes, puesto que se presentaba como un nuevo régimen estético, es decir, como un nuevo sistema de visibilidad y composibilidad histórica de las obras de arte (Rancière J., 2014: 13).

2 De acuerdo a esto, la literatura es política según Rancière, en la medida en que está compuesta a partir de la tensión de tres democracias o formas de igualdad. Primero, la democracia de una palabra muda depositada sobre el cuerpo de las cosas que habla mejor que cualquier orador del pueblo. En segundo lugar, la democracia de una palabra, sin amo ni destino, disponible para componer la historia de cualquier vida (cuestión que rompía con las jerarquías sociales del sistema representativo, donde sólo algunos seres eran dignos de una historia). Finalmente, una tercera democracia que viene a refutar a las anteriores, ya que propone la democracia "molecular" de los estados o los hechos sin razón (Rancière J., 2007).

De este modo, Rancière parece haber dado las claves para comprender claramente cuáles son las políticas de la literatura, cómo es que ellas han funcionado 
transformando las prácticas y teorías artísticas, así como también el discurso de otras disciplinas, como la historia, la filosofía, la psicología, entre otras ${ }^{1}$. Sin embargo, es difícil comprender desde la perspectiva de Rancière cómo es que la literatura irrumpe en un determinado campo cultural y artístico, y de qué manera puede estar comprometido el escritor o sus iniciativas editoriales, en la aparición y creación de nuevas condiciones y trayectos para sus obras.

Dicho en otras palabras, ante el interés de definir tan lúcidamente qué es lo que ha hecho posible en términos estético/políticos el surgimiento de la literatura, parece haber quedado, en parte, oscurecida aquella inquietud del escritor o artista por convertirse en el propio agente de producción y promoción de su obra. Y, aunque es claro que aquella política con la que el escritor se conduce empíricamente no coincide necesariamente con la sensibilidad política que propone su obra, quizás sí sea posible afirmar que la política del escritor consiste en generar las condiciones de posibilidad o los medios que hacen que su obra aparezca dentro de un determinado campo literario.

5 En relación a lo anterior, si recordamos tanto la noción de autor como la de obra que nos proponía Michel Foucault hacia 1970, observaremos que ambas figuras aparecían como determinadas formas de ejercer un control sobre el discurso, de concentrarlo, regularlo o neutralizarlo imponiéndole un determinado orden (Foucault M., 1994: 811)2 . Sin embargo, años más tarde, será el mismo Foucault quien se interrogará a propósito de escritores "locos" como Raymond Roussel o Pierre Rivière: "¿qué es lo que hace que algunos [textos] sean sacralizados y pasen a funcionar como "literatura"? (Foucault M., 2008: 65) y, en qué medida estos discursos pueden ser considerados también como políticamente subversivos.

Me gustaría captar más bien el movimiento, el pequeño proceso, por el que un tipo de discurso no literario, desatendido, olvidado apenas pronunciado, entra en el campo literario. ¿Qué es lo que sucede ahí? ¿Qué se desencadena? ¿Cómo se modifica ese discurso en sus esfuerzos por el hecho de ser reconocido como literario? (Foucault M., 2008: 67)

6 La respuesta de Foucault, si comprendemos que esta interrogante se produce dentro de un determinado momento de su reflexión, radica en la cuestión del poder. Así como ocurría con aquellas vidas infames que ingresaban a un determinado orden del discurso ${ }^{3}$, para Foucault es mediante el choque o la confrontación con determinadas formas de poder que determinadas obras podrán aparecer dentro de una "institucionalidad" literaria. Más aún, para Michel Foucault ha sido la institución universitaria aquella que, a partir del siglo XIX, ha servido como "plataforma" para definir qué es la literatura contemporánea, realizando además su propia crítica. A partir de allí, literatura y universidad no habrían dejado de confundirse, por lo que "se sabe perfectamente que hoy en día la literatura llamada de vanguardia sólo es leída por universitarios" (Foucault M., 2008: 63).

De este modo, nos encontramos con dos visiones con respecto al carácter político de la literatura. Por un lado, Rancière nos hablará de la política de la palabra literaria, en cuanto ésta encarna un nuevo reparto o distribución de lo sensible (Rancière J., 2000). Mientras que, para Foucault, una determinada configuración de lenguaje se transforma en literatura, en la medida en que un discurso ingresa o traspasa el umbral de una determinada "institución" literaria, mediante una relación de poder. Más aún, es posible afirmar con respecto a este último filósofo, que muchos de aquellos textos considerados como "no-literarios" (textos históricos, biográficos, periodísticos, etc.) 
fueron utilizados en su obra con el fin de hacer estallar el "monocentrismo" de la literatura (Piégay-Gros N., 2004).

De cualquier modo, podemos preguntarnos si estas dos lecturas sobre la literatura y su política son necesariamente antagónicas o, si más bien, ellas pueden convivir con respecto a la forma en que una obra aparece dentro de nuevos circuitos culturales y artísticos. Se trata, por una parte, de afirmar el carácter estético y político de la literatura, con respecto a la manera en que una obra instala una determinada configuración de lo sensible que rompe con el ordenamiento simbólico de las cosas, los tiempos y lugares y, por otra parte, de observar la manera en que esta obra literaria se instala en una comunidad mediante la política del escritor, esta última ya no concebida como la política de la obra, sino como aquella política editorial que trabaja por las condiciones de posibilidad de su aparición y divulgación.

9 A partir del actual fenómeno de editoriales independientes en Chile, quisiéramos acompañarnos de Rancière cuando nos hablaba en Breves viajes al país del pueblo de aquellos "apóstoles-artistas", que debían inventar una nueva praxis y nuevo lenguaje para divulgar la "palabra" sansimoniana (Rancière J., 2012) y observar de qué manera el escritor se ha transformado también en un "apóstol" de su obra, abriéndole nuevas posibilidades de aparición y nuevos trayectos de circulación.

Dicho con otras palabras, si la política es realizada según Rancière por "animales literarios", es decir, por animales que emiten una palabra que expresa otra sensibilidad o un nuevo mundo allí donde sólo se observaba uno (Rancière J., 2012: 53), queremos plantear la posibilidad de considerar al escritor como un "animal político", no únicamente por el hecho de que hace literatura o porque la sensibilidad de su obra es política, sino también por el hecho de abrir nuevos caminos de producción y difusión, nuevos espacios y circuitos para la aparición de su obra y la de otros escritores, en definitiva, por democratizar aquellos espacios donde una determinada comunidad no esperaba ni escritores ni obras literarias.

\section{El surgimiento colectivo de las editoriales independientes en Chile}

11 La emergencia de la edición independiente en Chile se produce durante los años 1990, como correlato de la "vuelta a la democracia" en este país, tras un período de 17 años de fuertes restricciones culturales, políticas y sociales ejercidas por la dictadura militar. Los nuevos proyectos de edición independiente aparecen entonces como un actor que viene a conectar el campo cultural y político, puesto que pone en discusión las iniciativas culturales propuestas por los gobiernos de "transición", allí donde se perpetúan o interrumpen determinadas políticas instauradas por la dictadura, o bien, se heredan lógicas económicas de carácter neoliberal que van en desmedro del libro, considerado éste como "cualquier otra mercancía", sin que se le asigne un estatuto diferencial que lo considere un bien simbólico y cultural (Symmes C., 2015).

En relación a lo anterior, la principal estrategia que asumirán los nuevos editores independientes consistirá en organizarse a modo de colectivos, asociaciones, o mediante un trabajo de alianzas que les permitiría realizar diversas ferias del libro, encuentros, foros, entre otras intervenciones y actividades públicas, permitiéndoles no 
sólo difundir sus catálogos, sino además instalar un debate sobre el libro y la cultura. De allí, que entre las principales formas de acción se destaque:

en primer lugar, el desarrollo - consistente en el tiempo- de una capacidad organizativa de trabajo en redes a diferentes escalas, que va desde lo regional a lo local, y desde ahí a lo supranacional; en segundo lugar, el despliegue de su experticia asociativa como una estrategia de resistencia colectiva. $Y$ en tercer lugar, sus modos de incursión en el espacio público, caracterizados por una suerte de militancia cultural, que lo ha dotado de un importante capital simbólico (Symmes C., 2015).

13 El carácter "independiente" de los nuevos editores se comprenderá entonces, a partir de su oposición a los grandes conglomerados de edición de carácter transnacional, en la manera de concebir el libro y su función cultural. Mientras que, en las grandes editoriales el libro está inmerso dentro de un vertiginoso flujo de producción "estandarizante", los editores independientes conciben al libro como un "vector cultural", de carácter simbólico y formativo, siendo un elemento determinante para la construcción de una ciudadanía lectora y crítica. Por otra parte, la noción de independencia que puede ser atribuida a las editoriales que surgen a partir de los años $1990 \mathrm{y}$, que a partir de nuevas experiencias ha tomado gran consistencia hoy, puede ser utilizada para identificar un sector de edición cuya producción es más bien "restringida", en cuanto al volumen de sus ediciones, sus modos de funcionamiento y distribución, la cantidad de géneros abarcados por su catálogo, así como por el grado de experiencia o profesionalización de sus gestores (Symmes C., 2015).

14 Ahora bien, a pesar de las limitaciones económicas, administrativas o de difusión que puedan presentar las nuevas editoriales, su relevancia radica en la apuesta que realizan al conformar sus catálogos a partir de autores emergentes o, muchas veces, a partir de escritores cuyas obran no han contado con una publicación o difusión necesarias que las diera a conocer. Asimismo, estas nuevas editoriales independientes no sólo desarrollan un trabajo de visibilización o "rescate" cultural, sino que además promueven obras que instalan un debate sobre la realidad social, cultural y política, tanto a nivel nacional como internacional. Quizás, el hecho de producir libros a una menor escala de producción termine siendo un elemento catalizador en la experimentación de nuevos formatos, reincorporando el carácter o factura "artesanal" del libro, o bien convirtiéndolo íntegramente en un "objeto" estético.

\section{Proyectos editoriales independientes en Chile: hacia una "política estética" de la edición}

15 Teniendo como referente experiencias de alianza de editores independientes a nivel internacional ${ }^{4}$, surge en el año 2001 la Asociación de Editores Independientes de Chile, considerada como la primera asociación de este género en América Latina. Si bien, en un inicio esta agrupación estaba compuesta por un número menor de editoriales, en la actualidad la conforman más de 50 editoriales autónomas y universitarias, concentrando gran parte de la edición nacional ${ }^{5}$. Dentro de sus propósitos, está asociación pretende "promover el desarrollo de la industria editorial nacional y latinoamericana, fortaleciendo los lazos de colaboración e intercambio" (Editores de Chile: Asociación). Asimismo, se propone fomentar la actividad cultural y potenciar un "ecosistema" sustentable para el libro y las editoriales, junto con "apoyar la elaboración e implementación de políticas públicas en torno al libro y la lectura" 
(Editores de Chile: Asociación), así como también a abolir el IVA (Impuesto de Valor Agregado) que se aplica al libro impreso, el cual en el caso chileno es el más alto del mundo (19\%), manteniéndose actualmente desde que fue implementado por la dictadura militar ${ }^{6}$.

Cabe destacar que dentro de sus prácticas de fomento a la lectura y la "bibliodiversidad", la Asociación de Editores Independientes ha logrado consolidar sus propios espacios de difusión. Por un lado, ha generado la ya conocida Primavera del libro, feria donde expone un centenar de editoriales chilenas y latinoamericanas, alcanzando ya su quinta versión. Por otro, esta asociación ha logrado incorporarse también en distintas ferias del libro, a nivel nacional e internacional, logrando expandir aún más la diversidad de sus catálogos (Editores de Chile, Calendario de ferias) ${ }^{7}$.

Por otra parte, existe un circuito de editoriales autónomas aún más reciente, pero no menos influyente y decisivo a la hora de colectivizar los esfuerzos para la publicación de escritores nacionales, así como para generar un debate en torno a las políticas sobre el libro. Es el caso de Cooperativa de Editores de la Furia (CEF), así como el de otras editoriales autónomas que establecen alianzas aleatorias para volver a experimentar sobre el "objeto" libro e interrogarse sobre las políticas de la sensibilidad literaria y las prácticas colectivas del escritor-editor.

18 En relación a los proyectos editoriales pertenecientes a Editores de la Furia ${ }^{8}$, podemos observar un marcado interés por resaltar el carácter político del editor. Para ello, han desarrollado una práctica colectiva cuya "unión se basa en la complicidad ante el oficio editorial", poniendo un marcado énfasis en democratizar los espacios de "acceso al libro y el desarrollo de la industria editorial, en particular en los espacios geográficos y culturales marginados" (Editores de la Furia: Quiénes somos). De esta manera, dentro de sus políticas se encuentra la idea de generar nuevas audiencias de lectura, mediante la participación y el desarrollo de diversas presentaciones públicas y ferias como la Furia del Libro.

19 El proyecto colectivo de Editores de la Furia ha sido tan decisivo estos últimos años que puede decirse que en la actualidad moviliza un "tercio" de la oferta editorial chilena (Santiago, J., 2016), apostando sobre todo por la publicación de aquellos escritores jóvenes que han quedado al margen de la gran industria editorial. Es por ello, que definen su trabajo como una "resistencia" en relación a la gran disparidad económica y de espacios de promoción que poseen las grandes editoriales transnacionales 9 .

20 Ahora bien, si dentro de esta gran proliferación de editoriales independientes lo que aparece con mayor énfasis es la política colectiva del "editor", lo que no puede pasarse por alto es que la mayoría de estas editoriales está conformada por "escritores" ${ }^{10}$. Han sido en gran parte poetas, narradores, ensayistas, etc., quienes han decidido producir sus propias obras y espacios de producción y difusión haciendo frente al desinterés de las grandes industrias editoriales. Esto último, no sólo las ha llevado a colectivizar sus esfuerzos para tener una mayor influencia y visibilidad dentro de la sociedad, sino que les ha dado la posibilidad de aventurarse hacia nuevas formas de sensibilidad, ya sea, por la incorporación en sus catálogos de la escritura de autores emergentes, o bien, por el rescate de obras y autores que históricamente han tenido una escasa difusión; ya sea, por los riesgos estéticos -e incluso económicos- que estas editoriales han asumido al volver a transformar al libro en un "objeto" estético, o bien, por salir en la búsqueda de nuevos formatos de producción y difusión que acerque distintos tipos de escritura a variados tipos de público. Todo esto, como señalábamos, a través de una actitud gremial 
que intenta plantear una discusión no sólo en torno al libro, sino también en torno al rol político del escritor-editor.

21 Uno de los casos que puede resultar llamativo con respecto al aprovechamiento de las potencialidades estéticas del libro, puede observarse en el proyecto que desarrolla actualmente la editorial Libros del Pez Espiral ${ }^{11}$, la cual nutriéndose principalmente de la tradición surrealista chilena y europea, ha decidido "integrar la mecánica del azar como un elemento constitutivo de la formación del catálogo" (Libros del Pez Espiral: Editorial), asumiendo que la objetualidad y la materialidad pueden ser vistas como cualidades "transgresoras" del libro.

En este sentido, es probable que Libros del Pez Espiral sea una de las recientes editoriales independientes que más haya innovado estéticamente con respecto al "objeto" libro, asumiendo diversas líneas de colección (Pez Espada, Pez Dorado, Pez Martillo, Pez Ilustrado, etc.), cada una de ellas transformando no solo la materialidad con que tradicionalmente se confeccionan las obras escritas (incorporando cartón, cuero, metal, cáñamo, etc.), sino también estableciendo una fusión de géneros (escritura, música, dibujo, diseño), cuestión que por su novedad amplía también el tipo de audiencias interesadas en adquirir sus publicaciones. Podría decirse incluso, que esta editorial se ha propuesto desarrollar lúdicamente un tipo de "merchandisig" basado en objetos estéticos (magnetos, bolsas de papel y de género, separadores de página, bolsas de té, etc.) que acompañan la propuesta de diseño de sus libros, haciendo de la editorial una especie de "marca" estética.

Figura 1: Libros y objetos de la editorial Libros del Pez Espiral

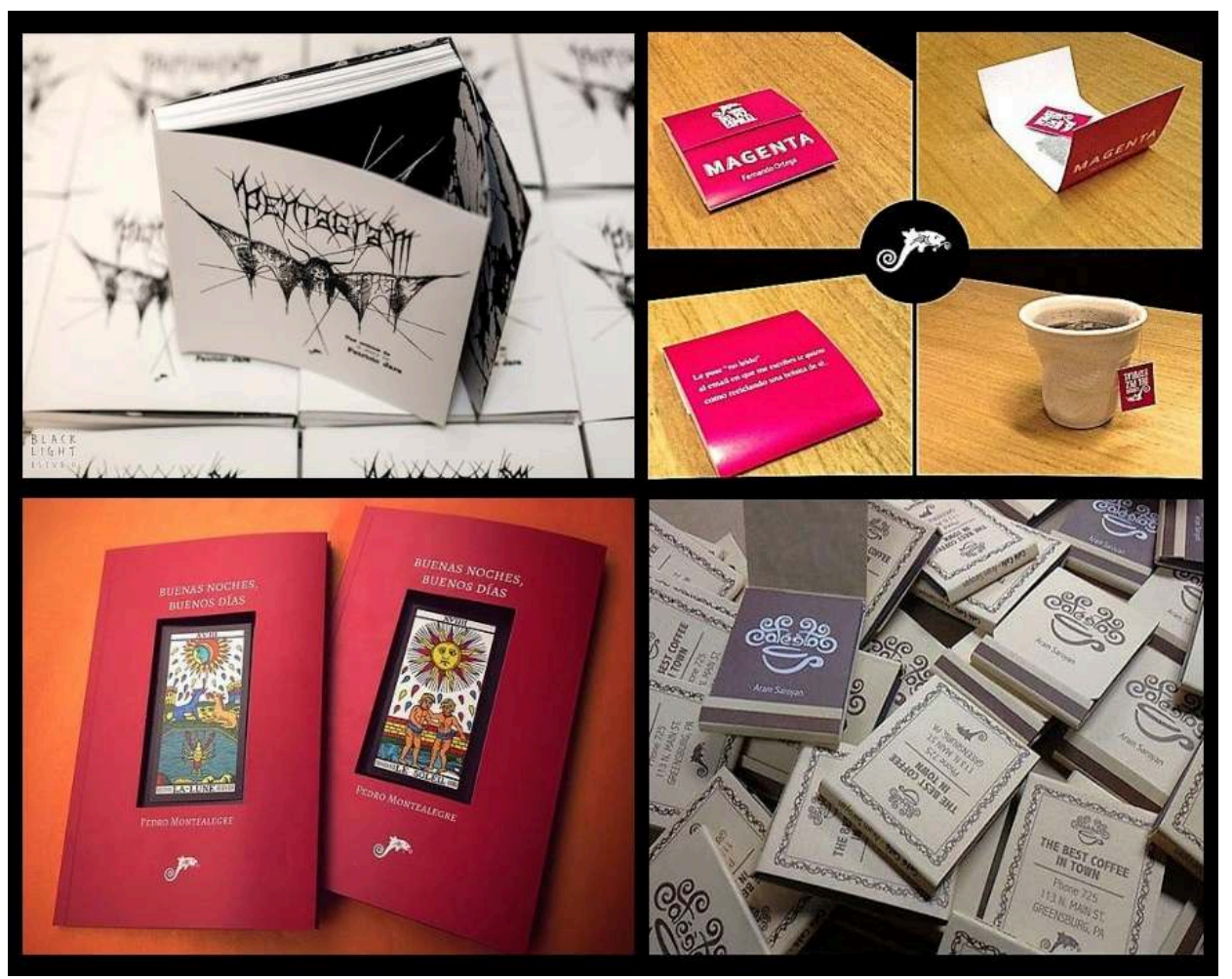

De izquierda a derecha: 1) Libro: Pentagram. Patricio Jara, 2014; 2) Objeto: Té Magenta, 2015; 3) Libro: Buenas noches, Buenos días. Fernando Montealegre, 2015; 4) Libro poesía visual: Café Café. Aram Saroyan. Trad. Carlos Soto, 2015. Libros del Pez Espiral, http://www.librosdelpezespiral.cl, página consultada el 7 de octubre de 2016. 
Otro proyecto editorial que se ha atrevido a innovar en sus formatos es Cuadro de Tiza Editores, cuya propuesta de edición plantea un rechazo al libro como "objeto de consumo" para establecer, más bien, una "resistencia de la plaquette", concebida esta última como breves cuadernillos diseñados y elaborados por sus propios editores (Cuadro de Tiza: Prensa). La sencillez del formato plaquette le ha permitido a esta editorial exhibir su amplio catálogo en diversas ferias del libro de carácter independiente, a un muy bajo costo económico que lo hace accesible a todo público.

Figura 2: Plaquettes Cuadro de Tiza Editores

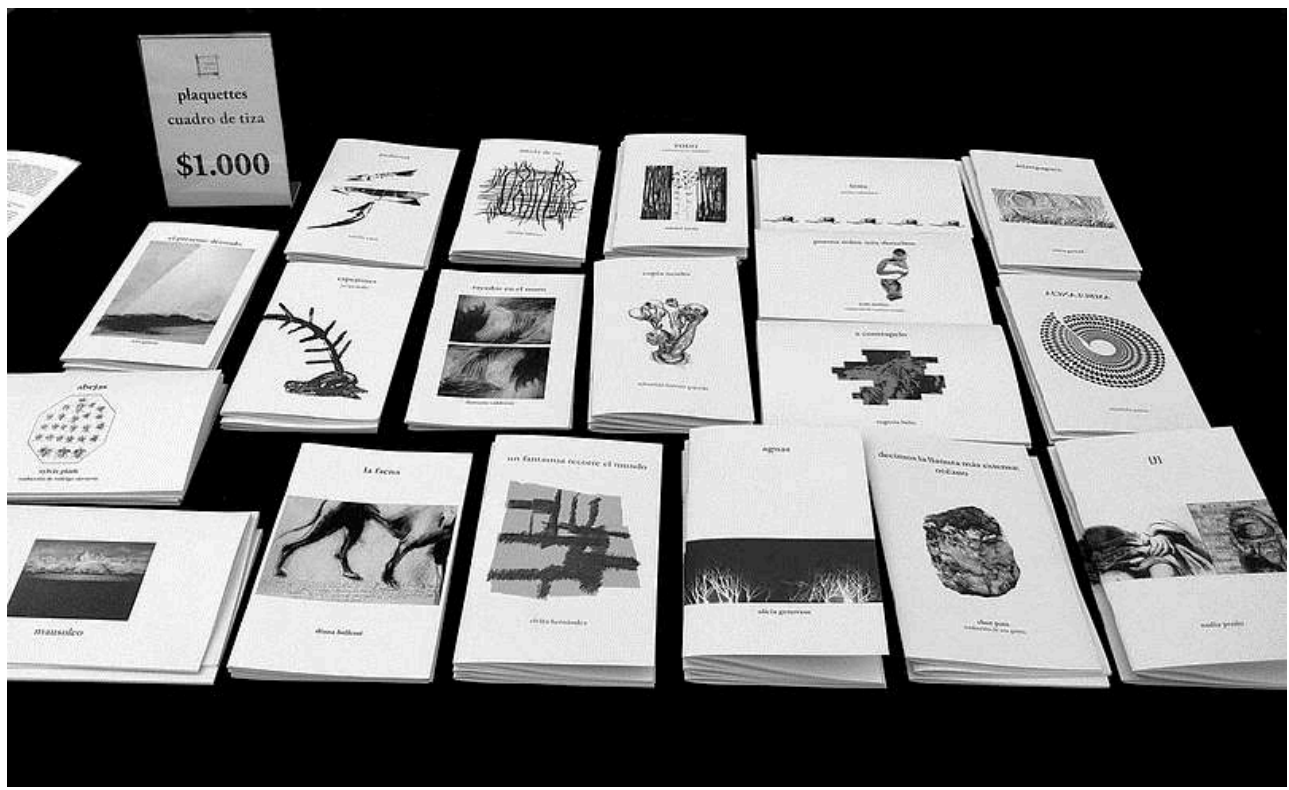

Como parte del catálogo de ensayos de Cuadro de Tiza Editores, se encuentran: La escritura que excede de Elizabeth Collingwood-Selby (2014); La sobrevivencia cínica de la subjetividad de Sergio Rojas (2013); la traducción de La palabra ascendente de Maurice Blanchot. Asimismo, dentro su catálogo de poesía encontramos los textos: [J] de Nadia Prado (2012); Un fantasma recorre el mundo de Elvira Hernández (2012); A contrapelo de Eugenia Brito (2012); Aquas de Alicia Genovese (2012). Cuadro de Tiza Editores, http://cuadrodetiza.wixsite.com/cuadrodetiza, página consultada el 3 de abril de 2017.

Constituido también por poetas y ensayistas ${ }^{12}$, el proyecto editorial Cuadro de Tiza se ha planteado también acercar la reflexión filosófica y estética al público, mediante la publicación de ensayos y traducciones de diversos filósofos y críticos contemporáneos que acentúan los vínculos entre poesía y pensamiento. Asimismo, el catálogo de esta editorial ha apostado no solamente por la publicación de los recientes trabajos de escritores jóvenes o emergentes, sino que además en él es posible visibilizar un "rescate" de diversas obras de poetas mujeres chilenas que han tenido una escasa difusión a nivel nacional (Cuadro de Tiza: Prensa).

Dentro de otros proyectos editoriales compuestos por poetas, narradores y artistas visuales, encontramos también el caso de Editorial Desbordes ${ }^{13}$, proyecto fundado el año 2011, el cual surge primero como colectivo político-estético que buscaba "ampliar los registros y circuitos destinados para la movilización de la cultura", promoviendo el desarrollo de diversas actividades e intervenciones públicas, donde confluían poetas, músicos, artistas visuales, gestores culturales de distintos sectores periféricos de Santiago ${ }^{14}$. Por medio de la gestión de prácticas políticas y sociales, Editorial Desbordes no sólo buscaba promocionar a los autores que comenzaban a componer su catálogo, 
sino que también se proponía "desarrollar espacios de discusión y disenso con respecto a las diversas relaciones entre la literatura, la estética y la política en la actualidad" (Editorial Desbordes: Nosotros). En relación a esto último, puede decirse que ya las primeras publicaciones de Desbordes, proponían una lectura de tipo rancièrana para comprender las políticas de su proyecto creativo y editorial:

la acción que el poeta, el artista desarrolla sea en la escritura del poema u otra intervención audio-visual, musical, estética en general, puede ser percibida y pensada como una entre múltiples formas de manifestar el disenso que configura su propio espacio antagónico a lo policial. Hacer política, por tanto, sería pensar de otra forma la política, como una cuestión de sensibilidad y no como el mero ejercicio del poder, sino como una experiencia de lo sensible que arriesga pensar desde otro lugar el pueblo y su emancipación (Donoso A. y Farias R., 2011).

Con el propósito de explorar en nuevas sensibilidades poéticas y formatos de difusión, Editorial Desbordes publica el año 2013 la colección Mil Plaquettes de Poesía, impresión ostentosa que, en formato plaquette, combinaba la escritura de jóvenes poetas chilenos con ilustraciones y diseños de diversos artistas visuales. De esta manera, este proyecto editorial se sumaba a otras tantas iniciativas de edición interesadas en explotar las posibilidades estéticas del objetivo libro, o bien, en experimentar con otros formatos de producción y difusión poética.

Figura 3: Portadas de plaquettes y libros de Editorial Desbordes
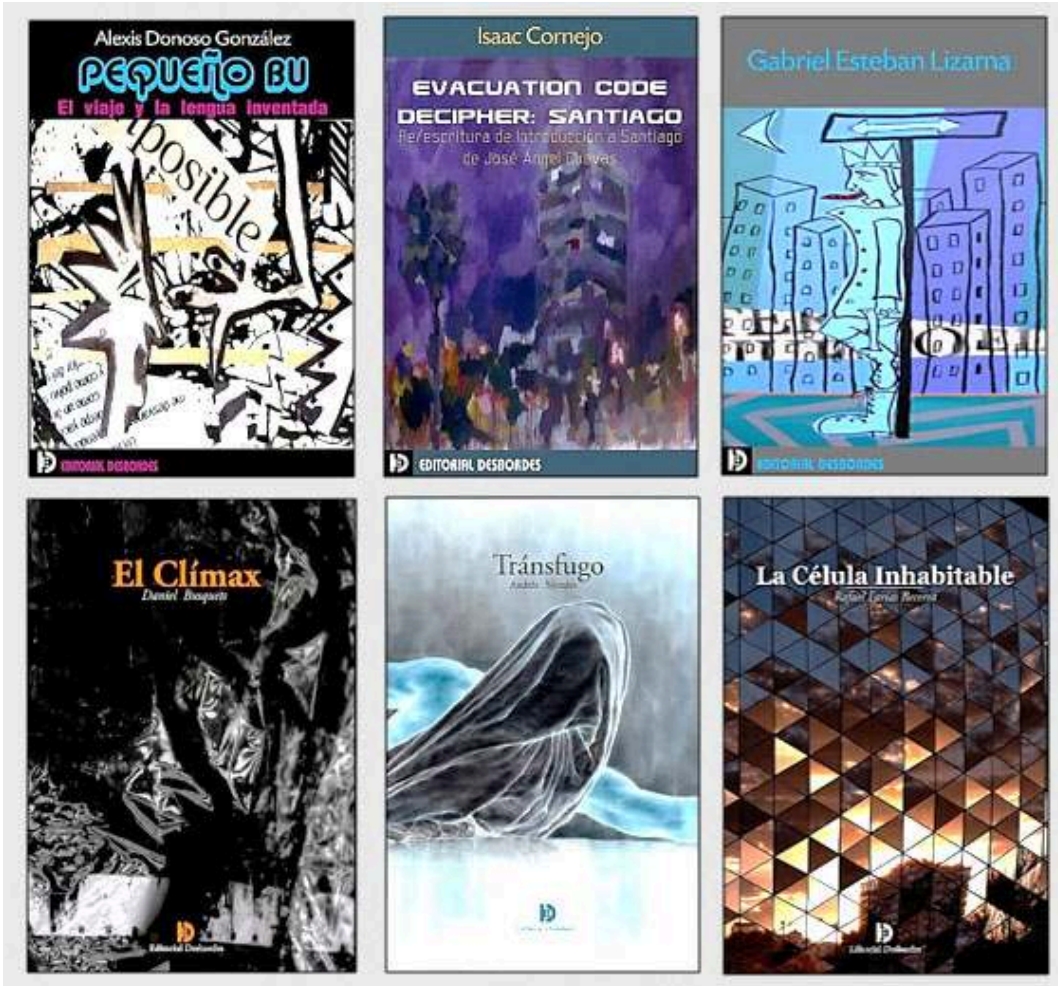

De izquierda a derecha: 1) Plaquette: Pequeño Bu. Alexis Donoso, 2013; 2) Plaquette: Evacuation Code Decipher: Santiago. Isaac Cornejo, 2013; 3) Plaquette: Poemas. Gabriel Lizama, 2013; 4) Libro: El Clímax. Daniel Busquets, 2015; 5) Libro: Tránsfugo. Andrés Morales, 2016; 5) Libro: La célula inhabitable. Rafael Farías, 2013. Editorial Desbordes, http://www.editorialdesbordes.cl/, página consultada el 7 de octubre de 2016. 


\section{A modo de conclusión}

27 El período de "transición democrática" en Chile ha traído consigo un nuevo actor cultural que viene a cuestionar a través de una estrategia gremial, la descomposición social y cultural llevada a cabo durante el régimen militar, una vez que la oferta editorial parecía estar coaptada o administrada por los grandes conglomerados de edición transnacional. Así, las nuevas editoriales independientes o autónomas comenzaban a instalar un debate acerca de la concepción del libro como "simple mercancía", para rescatar su valor simbólico, formativo y crítico, de modo que su producción y difusión no quedara sujeta a los avatares del mercado o a las políticas culturales de los gobiernos de turno.

28 Ante un panorama post-dictatorial, podría decirse que la función de las primeras asociaciones de editores independientes ha sido crear y dinamizar espacios de producción, difusión y encuentro con el libro, luego de un prolongado período de escasez de proyectos editoriales y de un bajo interés por la lectura. En este sentido, si las editoriales independientes o autónomas en Chile han logrado movilizar hoy el gran flujo de escrituras emergentes, esto se debe a su política de carácter gremial o colectiva, que les ha permitido conformar nuevas alianzas y espacios de difusión (principalmente ferias, tales como La primavera del libro, La Furia del libro, FLIA, entre otras), logrando atraer así nuevos públicos a partir de una variada oferta cultural.

Ahora bien, más allá de que estas editoriales sean gestionadas o administradas por editores de profesión, gestores culturales o personas naturales aficionadas a la literatura y la crítica, quienes están detrás de la gran mayoría de los proyectos editoriales independientes son "escritores" y "escritoras". Han sido en su mayoría poetas, narradores, ensayistas, críticos, etc. quienes han formado sus propias editoriales haciendo frente al desinterés de las grandes casas editoriales por sus obras o por la difusión cultural, debido a una relación principalmente mercantil con respecto al libro.

El hecho de que el escritor haya decidido transformarse en el "editor" de sus propias obras o de la de sus pares, le ha permitido, por una parte, mantener una mayor autonomía en su gestión económica y editorial, lo cual le posibilita establecer vínculos más libres con los autores que conforman su catálogo, así como establecer alianzas con otras editoriales. Por otra parte, la posibilidad de manejar con relativa autonomía los procesos de edición, le ha permitido al escritor-editor potenciar la propuesta estética de sus publicaciones, ya sea explotando las posibilidades materiales y simbólicas del libro, o bien, innovando en la creación de nuevos formatos y diseños (como es el caso de las plaquettes), haciendo de la escritura una experiencia más cercana y accesible al público.

31 En cualquier caso, el trabajo de edición asumido por los escritores no sólo nos habla de un interés por democratizar los espacios de producción y difusión del libro, transformándose en un actor cultural relevante para el incentivo de la lectura, la creación literaria o el pensamiento crítico, sino que también nos habla de la búsqueda de nuevas sensibilidades posibles de encontrar, tanto en la escritura de los nuevos escritores que estas editoriales se arriesgan a publicar, así como en la experimentación de nuevos formatos de publicación que, en muchos casos, potencian una determina obra transformándola en un complejo objeto estético. De este modo, es que se observa 
también una política y una estética de la edición, promovida esta vez por el escritor como un incansable militante de la sensibilidad inaprensible de su obra.

\section{BIBLIOGRAPHIE}

Cuadro de Tiza Editores, http://cuadrodetiza.wixsite.com/cuadrodetiza/la-editorial, página consultada el 3 de abril de 2017.

Donoso, Alexis y Farías, Rafael, Dêmos, Santiago de Chile, Editorial Desbordes, 2011.

Donoso, A., “Entrevista", El ciudadano, Agosto 2016, Santiago de Chile, Diario, /Año 12/ Nº188.

Editores de Chile, http://editoresdechile.cl/, página consultada el 5 de octubre de 2016.

Editores de la Furia, http://www.editoresdelafuria.cl/, página consultada el 6 de octubre de 2016.

Editorial Desbordes, http://www.editorialdesbordes.cl/, página consultada el 7 de octubre de 2016.

Farías, Eduardo, «Edición independiente: discusiones que faltan», https:// poesiaycritica.wordpress.com/2015/12/30/edicion-independiente-discusiones-que-faltan/, página consultada el 3 de abril de 2017.

Foucault, Michel, « Desembarazarse de la filosofía (1975) » en Entrevistas con Michel Foucault, Buenos Aires, Editorial Paidós, 2008. Entrevistas realizadas por Roger Pol-Droit.

Foucault, Michel, El orden del discurso, Buenos Aires, Tusquets Editores, 1992.

Foucault, Michel, « Qu'est-ce qu'un auteur? » en Dits et écrit I (1954-1969), Paris, Éditions Gallimard, 1994.

Foucault, Michel, « La vie des hommes infâmes » en Archives de l'infamie, Paris, Editions Les prairies ordinaires. 2009. Obra reunida por el colectivo Maurice Florence, compuesto por los historiadores y filósofos: Philippe Artières, Jean-François Bert, Pascal Michon, Mathieu PotteBonneville et Judith Revel.

Libros del Pez Espiral, http://www.librosdelpezespiral.cl, página consultada el 7 de octubre de 2016.

Piégay-Gros, Nathalie, «La critique littéraire et la pensée de Michel Foucault » en La littérature et les arts, Paris, Éditions Kimé, 2004.

Rancière, Jacques, Le partage du sensible, Paris, La Fabrique éditions, 2000.

Rancière, Jacques, Politique de la littérature, Paris, Éditions Galilée, 2007.

Rancière, Jacques, El desacuerdo. Política y filosofía, Buenos Aires, Nueva Visión, 2012.

Rancière, Jacques, La parole muette, Paris, Hachette Pluriel, 2014.

Rancière, Jacques, Courts voyages au pays du peuple, Paris, Éditions du Seuil, 2015.

Santiago, Jesús, "Editoriales independientes de Chile ganan influencia”, Grupo Milenio, 26 de mayo de 2015, http://www.milenio.com/cultura/editoriales_independientes_Chile- 
Feria_Internacional_del_Libro_de_Santiago_0_524947505.html, página consultada el 12 de octubre de 2016.

Symmes, Constanza «Editar (en) el Chile post-dictadura: Trayectorias de la edición independiente », Nuevo Mundo Mundos Nuevos [En ligne], Questions du temps présent, 18 septiembre 2015, http://nuevomundo.revues.org/68211, página consultada el 3 de abril de 2017.

\section{NOTES}

1. En relación a las transformaciones que la literatura, como nuevo régimen estético/político efectuó en el discurso de la historia, la sociología, la psicología, entre otras disciplinas, Jacques Rancière afirma que: "Las críticas del siglo XX han creído, en el nombre de la ciencia marxista o freudiana, de la sociología o de la historia de las instituciones o las mentalidades, desmitificar la ingenuidad literaria y enunciar su discurso inconsciente, mostrando cómo estos discursos cifran sin saberlo las leyes de la estructura social, el estado de las luchas de clases, el mercado de los bienes simbólicos o la estructura del campo literario. Pero los modelos explicativos que ellos han utilizado para decir lo verdadero sobre el texto literario son los modelos forjados por la literatura misma. Analizar las verdades prosaicas como fantasmagorías que llevan el testimonio de la verdad oculta de una sociedad, decir la verdad de la superficie viajando en las profundidades y enunciando el texto social inconsciente que ahí se descifra, este modelo de la lectura sintomática es invención propia de la literatura" (Rancière, J., 2007).

2. Michel Foucault, en la primera versión francesa de Qu'est-ce qu'un auteur?, planteará que "el autor no es una fuente indefinida de significaciones que se colmarían en la obra, el autor no precede a las obras. Existe un cierto principio funcional mediante el que, en nuestra cultura, se delimita, se excluye, se selecciona: en una palabra, el principio mediante el que se obstaculiza la libre circulación, la libre manipulación, la libre composición, descomposición, recomposición de la ficción. Si estamos acostumbrados a presentar al autor como genio, como surgimiento perpetuo de novedad, es porque en realidad lo hacemos funcionar de un modo exactamente inverso. Diremos que el autor es una producción ideológica en la medida en que tenemos una representación invertida de su función histórica real. El autor es pues la figura ideológica mediante la que se conjura la proliferación del sentido" (Foucault, M., 1994).

3. En el texto La vie des hommes infâmes, Foucault también nos hablará de un posible nacimiento de la literatura en Occidente, datado hacia finales del siglo XVII y comienzos del siglo XVIII, una vez que ésta asume aquella "gran" ética y política que hace pasar lo más banal e ínfimo de una sociedad al orden del discurso (Foucault, M., 2009).

4. En 1998, surge como primer referente la alianza internacional de Editores Independientes, formada por editoriales de cuatro países: Era (México), Trilce (Uruguay), Txalaparta (País Vasco, España) y LOM (Chile). (Symmes C., 2015).

5. Hacia el año 2001, Editores Independientes estaba compuesta únicamente por las editoriales Lom, Cesoc (Centro de Estudios Sociales), Cuarto Propio, Cuatro Vientos, Dolmen, Pehuén y Ril. No obstante, a partir del año 2003, esta agrupación comenzará a llamarse Editores de Chile. Asociación de Editores Independientes. Universitarios y Autónomos, debido a la cantidad de proyectos editoriales que se han incorporado a esta asociación. Entre ellas, es posible nombrar a: Adrede Editora, Amapola editores, Le monde diplomatique (Chile), Con fin Editores, Ebooks Patagonia, Edición Digital, Ediciones Arq, Ediciones Cetsur, Columba Ediciones, Ediciones del desierto, Ediciones del Ser: Editorial Universitaria, Ediciones Universidad Alberto Hurtado, Ediciones Universidad de Concepción, Editorial Universidad la Serena, Ediciones Universidad Tecnológica Metropolitana, Ediciones Universitarias de Valparaíso, Ediciones Universidad Católica Silva Henríquez, Editorial Amanauta, Editorial Forja, IES (Instituto de Estudios de la Sociedad), Editorial Maitri, Editorial 
Rica aventura, Editorial USACH, Ediciones Ekaré Sur, Ediciones El Desconcierto.cl, Gata Gorda Ediciones, J.C. Sáez Editor, Liberalia Ediciones, Editorial Mago, Editorial Mandrágora, Mythica Ediciones, Ocho libros editores, Ofqui editores, Peuma Ediciones, Editorial Quilqa, Quilombo Ediciones, Rapanui Press, Recrea Libros, Sa cabana Editorial, Signo editorial, Simplemente editores, Tajamar editores, Uqbar editores, Editorial Ventana Abierta, Editorial Segismundo. Editores de Chile, http://editoresdechile.cl/, página consultada el 5 de octubre de 2016.

6. Las condiciones de producción, distribución, exportación e importación del libro en Chile siguen siendo en la actualidad bastante precarias. Por un lado, el IVA que se aplica al libro es de un 19\%, siendo uno de los impuestos más altos en el mundo. Asimismo, su venta tampoco consta de un precio fijo. Por otra parte, existe una débil red de librerías, las cuales están distribuidas mayormente en la capital, siendo poco accesibles a las comunas de menores ingresos, a lo cual se suman índices preocupantes de disminución de la lectura a nivel nacional (Symmes C., 2015). Un estudio sobre el comportamiento lector en Chile, realizado el año 2011 por el Consejo Nacional de Cultura y las Artes, señala que el $84 \%$ de los chilenos entre 15 y 34 años no comprende adecuadamente textos largos y complejos. Del mismo modo, sólo un $6 \%$ de los encuestados declara que dentro de sus tiempos libres prefiere leer y, sólo un $26 \%$ señala leer mediante el libro impreso. Consejo Nacional de la Cultura y las Artes, 14 de diciembre de 2012, http:// www.cultura.gob.cl/institucional/estudio-de-comportamiento-lector/, página consultada el 1 de abril de 2017.

7. Entre las ferias en las que actualmente participa Editores de Chile se encuentran: FILSA (Feria Internacional del Libro de Santiago (Chile), FILBO (Feria Internacional del Libro de Bogotá (Colombia), FILMA (Feria Internacional del libro de Lima (Perú), Feria del Libro de Buenos Aires (Argentina), Feria Internacional del Libro Zócalo (México), Fiesta del libro y la Cultura Medellín (Colombia), Feria Internacional del Libro de Guadalajara (México), The London Book Fair (Inglaterra), Bologna Children's Book Fair (Italia), Liber. Feria Internacional del Libro (España), Frankfurter Buchmesse (Alemania). Editores de Chile, http://editoresdechile.cl/calendario-deferias/, página consultada el día 3 de abril de 2017.

8. Dentro de las editoriales que pertenecen a la Cooperativa de Editores de la Furia se encuentran: Ayún, Oxímoron, Imbunche, Emergencia Narrativa, Narrativa Punto Aparte, Letra Capital, Edicola Ediciones, Libros del Perro Negro, La Calabaza del Diablo, La Polla Literaria, Montacerdos, Cuneta, Alquimia, Mediagua, La Pollera, Sangría, Eleuterio, Nadar Ediciones, Una temporada en Isla Negra, Das Kapital, Balmaceda Arte Joven, Asterión, Sherezade, Libros de Mentira, Ceibo, Ediciones Puro Chile, Ajiaco Ediciones, Editorial Águila Azul, Cinco Ases, Grafito, Cuadro de Tiza, Descontexto, Libros del Cardo, Ediciones Overol, Estruendomudo CL, dibujame.cl, Pequeño Dios, Garceta, Laurel. Editores de la Furia, http://www.editoresdelafuria.cl/, página consultada el 6 de octubre de 2016.

9. En la actualidad, existe un acalorado debate acerca de las lógicas económicas que debieran seguir las editoriales independientes. A éstas se les reclama el haber comenzado a adoptar lógicas mercantiles similares al de las grandes marcas editoriales, perdiendo toda autonomía o independencia ante la gran industria del libro. Farías, Eduardo, «Edición independiente: discusiones que faltan", https://poesiaycritica.wordpress.com/2015/12/30/edicion-independientediscusiones-que-faltan/, página consultada el 3 de abril de 2017. No obstante, parece discutible la exigencia de una autonomía o independencia absoluta de las editoriales en relación al Estado u otras instituciones públicas o privadas. De pronto, por motivos también ideológicos, pareciera que las editoriales estuvieran impedidas de tener una economía que las movilizara o dinamizara, ante el prejuicio de que así funcionarían dentro de las mismas lógicas económicas de las grandes industrias editoriales. $Y$, aunque la precariedad de las actuales editoriales emergentes nos indica que nada puede estar más lejos de eso, debido a que su lucha hoy consiste más bien en la posibilidad de mantenerse o sobrevivir, habría que recordar que un libro es también un objeto, cuyos materiales para su producción tienen también un costo en el mercado, el cual no siempre 
puede ser solventado por los propios editores. Más aún, habría que aceptar que la apuesta de los editores independientes por publicar la obra de escritores desconocidos o emergentes tiene una profunda dimensión cultural. Por último, no se entiende bajo qué tipo de prejuicio habría que negar cierto aspecto mercantil de las editoriales independientes, si bien éstas necesitan diseñar, elaborar, producir, imprimir, difundir sus obras para subsistir, a sabiendas de que el mercado del libro independiente en Chile no ofrece grandes posibilidades de lucro.

10. Sólo por nombrar algunos escritores, ensayistas y artistas pertenecientes a Editores de la Furia, los cuales han formado sus propias editoriales, o bien, tienen un rol activo en ellas, encontramos a: Galo Ghigliotto de Editorial Cuneta; Guido Arrollo de Alquimia Ediciones; Pablo Lacroix y Nicolás Brino de Ajiaco Ediciones; Camilo Brodsky de Editorial Das Kapital; Gonzalo León y Marcelo Montecinos (fotógrafo) de Calabaza del Diablo; Gustavo Bernal y Marcelo Valdés de La Polla Literaria; Juan Manuel Silva, Diego Zúñiga y Luis López-Aliaga de Editorial Montacerdos; Rodrigo Hidalgo de Editorial Balmaceda Arte Joven; Carlos Almonte y Juan Carlos Villavicencio de Editorial Descontexto, entre muchos otros.

11. Editorial Libros del Pez Espiral está formada por los poetas Andrés Urzúa, Daniel Madrid, Camila Muñoz. Entre sus editores se encuentran Jaime Bristilo, Ernesto González, Carlos Soto. Libros del Pez Espiral, http://www.librosdelpezespiral.cl, página consultada el 7 de octubre de 2016.

12. Editorial Cuadro de Tiza está compuesta actualmente por los poetas y ensayistas: Julieta Marchant, Victor Ibarra, y Nicolás Labarca. Cuadro de Tiza Editores, http:// cuadrodetiza.wixsite.com/cuadrodetiza/la-editorial, página consultada el 3 de abril de 2017.

13. Editorial Desbordes está compuesta por los poetas: Gonzalo Geraldo, Salvador Troncoso, Isaac Cornejo, Alexis Donoso y Rafael Farías. Editorial Desbordes, http://www.editorialdesbordes.cl/, página consultada el 7 de octubre de 2016.

14. Como señala el poeta Alexis Donoso, Editorial Desbordes nace también como una investigación, la cual pretendía realizar un "análisis crítico de la poesía escrita desde la dictadura en adelante y su relación con la política. Queríamos llevar a cabo un proceso de desidentificación de estos modos de hacer poesía y política" (Donoso, A., 2016: 29).

\section{RÉSUMÉS}

Dans cet article, on présente la possibilité de concevoir la politique éditoriale de l'écrivain comme une autre politique littéraire. Pour cela, on considère l'émergence significative de maisons d'édition indépendantes au Chili, où l'écrivain a assumé le rôle d'éditeur, tant pour mobiliser sa propre écriture et celle de ses pairs, que pour produire des formats esthétiques innovants dans lesquels ses œuvres se publient. De cette façon, confluent sans doute une politique de la sensibilité littéraire et une politique de l'écrivain, ce dernier étant compris comme le producteur des conditions de possibilité et de circulation des œuvres.

En este artículo se plantea la posibilidad de concebir la política editorial del escritor como otra política literaria. Para ello, se expone sobre la aparición significativa de editoriales independientes en Chile, donde el escritor ha asumido el rol de editor con el propósito de movilizar su propia escritura y la de sus pares, así como también para innovar en el formato estético en que se presentan sus obras. De este modo, parecen confluir, tanto una política de la 
sensibilidad literaria como una política del escritor, concebida esta última como productora de las condiciones de posibilidad y de circulación de las obras.

This article considers the possibility of conceiving the writer- publisher policy as another literary policy serving alternative literary politics. To this effect, the article examines the meaningful emergence of independent publishing houses in Chile, where the writer has taken over the role of publisher with the purpose of mobilizing his or her writing and his or her peers' writing, as well as to create innovative aesthetic formats in which their works are presented. Thus, a politics of literary reception and the strategies of the writer seem to converge, the writer being considered as the producer of the conditions of existence and circulation of the works.

\section{INDEX}

Mots-clés : littérature, éditeur, politique, écrivain, presses indépendantes du Chili Palabras claves : literatura, editor, política, escritor, editorial independiente de Chile Keywords : Literature, publisher, politics, writer, independent publishing houses in Chile

\section{AUTEUR}

\section{RAFAEL FARÍAS BECERRA}

Licenciado en Educación en Castellano. Universidad de Santiago de Chile. Magister en Filosofía. Universidad de Chile. Doctor@ en Filosofía. Universidad de Chile-Universidad de Barcelona. Pasante Université París 8, Vincennes-Saint Denis. Director de Resonancias. Revista de Filosofía de Estudiantes de Postgrado de la Universidad de Chile. Fundador Editorial Desbordes, 2011. Profesor Comunicación Escrita. Universidad Diego Portales. rafael.farias@mail.udp.cl / rafaelfariasbecerra@gmail.com 